\title{
Research on Mechanical properties of Micro-aro Oxidation Ceramic Coatings on Magnesium
}

\author{
Gao cheng ${ }^{1}$, Zhou yiqun ${ }^{1}$, Hao jianmin ${ }^{2}$, Xu jinyong ${ }^{1 a}$ \\ ${ }^{1}$ School of Mechanical and Electrical Engineering, Guilin University of Electronic Technology, Guilin 541004, China \\ ${ }^{2}$ School of mechanical engineering, Chang'an University, Xian Shanxi 710064 China
}

Keywords: magnesium alloy; micro-arc oxidation; ceramic coatings; three-point bending method.

\begin{abstract}
The paper, to explore mechanical properties of magnesium alloy and ceramic coatings by micro-arc oxidation, through measurement of tensile modulus of elasticity of magnesium alloy matrix, three-point bending method to measure the elastic modulus of the ceramic coatings. The results show that: can get magnesium alloy matrix elastic modulus $\mathrm{E}=50.6 \mathrm{GPa}$, Poisson's ratio $v=0.3$, can get micro-arc oxidation ceramic coatings elastic modulus $\mathrm{E}=127.4 \mathrm{GPa}$, Poisson's ratio $v=0.3$. At the same time studied the relationship elastic modulus of the ceramic coatings with the thickness of the thickness between $20-60 \mu \mathrm{m}$. The results show that: With the increaseing of the thickness, the ceramic coatings elastic modulus trend to increase.
\end{abstract}

\section{Introduction}

In the study of mechanical properties of thin films is one of the most important parameters in elastic modulus of thin films, especially on the nano multicoatings film and ultra-thin films of "super hardness", "super modulus" effect, so the research on elastic modulus of films has attracted many researchers[1].

Through the experiment study showed that the[2], the surface of magnesium alloy micro arc oxidation treatment of containing $\mathrm{MgO}, \mathrm{MgAl} 2 \mathrm{O} 4$ and $\mathrm{Mg} 2 \mathrm{SiO} 4$ phase. Do mechanical test specimens, with increasing oxidation time, the ceramic coatings at the interface structure containing $\mathrm{MgO}$ are not the same, the change of properties of magnesium alloy. The elastic modulus of $\mathrm{Xu}$ lianyong[3] by three point bending method of a Fe based coating. The results show that, with the increase of coating thickness, modulus of elasticity. The analysis thinks, on the one hand, the thickness of coating, the higher measuring accuracy; on the other hand, the increase of coating thickness, the porosity decreased.

\section{The test material}

On the surface of magnesium alloy by microarc oxidation technology to produce ceramic coatings.

The matrix for AZ91B magnesium alloy, magnesium alloy sheet 3-1 for each element content, content of each element of the 3-2 ceramic coatings. 
Table1.The content of 3-1 AZ931B magnesium alloy elements (Wt\%)

The content of alloy

$\mathrm{Al}$

Zn

$\mathrm{Si}$

$\mathrm{Cu}$

$\mathrm{Ni}$

$\mathrm{Fe}$

$\mathrm{Mn}$

$\mathrm{Mg}$

Content $(\%)$

3.1

0.9

0.013

0.01

0.00053

0.003

0.23

Allowance

Table2. The content of the element 3-2 ceramic coatings (Wt\%)

The content of alloy

Content $(\%)$
$\mathrm{Mg}$

56.11
$\mathrm{O}$

30.65
$\mathrm{Na}$

0.07
P

13.17

\section{Experimental results and analysis}

3.1 The mechanical properties of magnesium alloy

\subsubsection{The elastic modulus of magnesium alloy}

The sample substrate made of AZ31B magnesium alloy sheet by wire cutting, tensile specimens cut provisions, its shape and size as shown in Figure 3-1, the test device using CMT5205 testing machine USA production as shown in Figure 3-2, assembled in the tensile testing machine static resistance strain gauge as shown in figure 3-3.

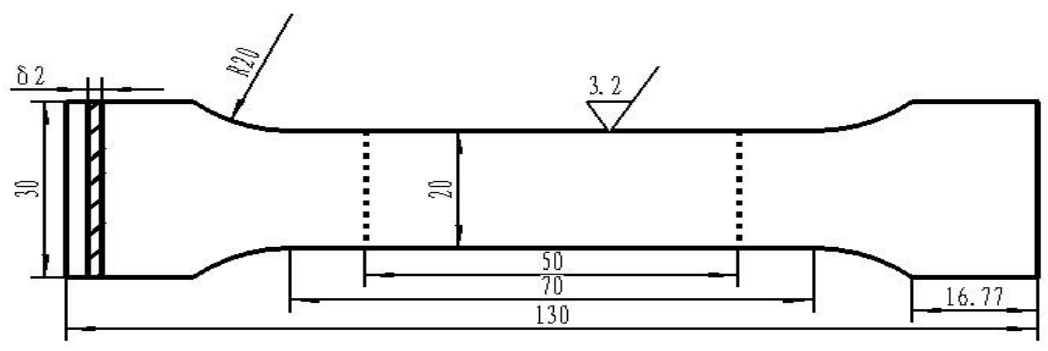

Figure 3-1 the shape and size of the tensile specimens 


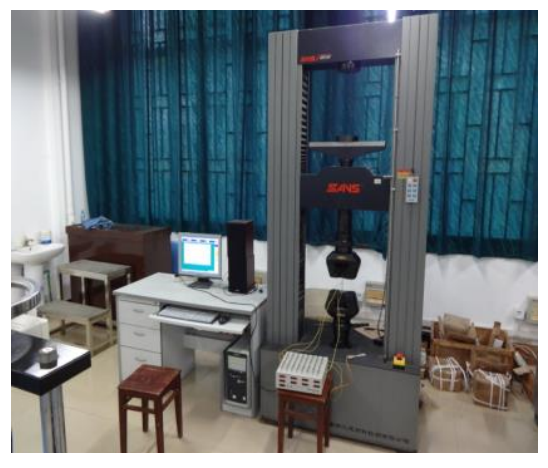

Figure 3-2

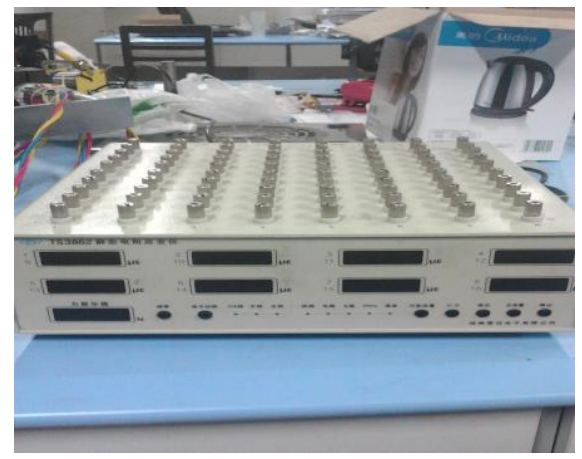

Figure 3-3

The tensile elastic modulus measurement method:

$$
\sigma=\mathrm{F} / \mathrm{A}, \quad \sigma=\mathrm{E} \times \mu \varepsilon
$$

A is the cross-sectional area of substrate, E is the modulus of elasticity.

By the formula (3-1) deformation can be

$$
\Delta \mathrm{F} / \mathrm{A}=\mathrm{E} \times \Delta \mu \varepsilon
$$

By the formula (3-2) can be obtained

$\mathrm{E}=\Delta \mathrm{F} / \mathrm{A} \Delta \mu \varepsilon$

In a tensile machine through the static resistance strain gauge records tension $\mathrm{F}$ and micro strain $\mu \varepsilon$, as shown in table $3-3$ records three groups of tension tension between $100 \sim 800 \mathrm{~F}$ and micro strain $\mu \varepsilon$ by the formula(3-3), the data of the three groups were calculated and the average elastic modulus, Can be the elastic modulus of matrix $\mathrm{E}=50.6 \mathrm{GPa}$.

Table 3-3 pull F and micro strain $\mu \varepsilon$

\begin{tabular}{lllllll}
\hline & $(\mu \varepsilon 1)_{1}$ & $(\mu \varepsilon 2)_{1}$ & $(\mu \varepsilon 1)_{2}$ & $(\mu \varepsilon 2)_{2}$ & $(\mu \varepsilon)_{3}$ & $(\mu \varepsilon 2)_{3}$ \\
\hline 100 & -43 & 119 & -38 & 131 & -69 & 159 \\
200 & -1 & 169 & -5 & 195 & -40 & 223 \\
300 & 37 & 223 & 36 & 224 & 3 & 227 \\
400 & 88 & 265 & 81 & 287 & 53 & 322 \\
500 & 135 & 311 & 139 & 342 & 99 & 372 \\
\hline
\end{tabular}


600

700

800
180

229

275
360

410

455
169

225

272
382

434

191

466

\subsubsection{The Poisson's ratio of magnesium alloy}

The ratio of transverse and longitudinal strain is known as Poisson's ratio. The Poisson's ratio of magnesium alloy floating around 0.3 in general, the Poisson's ratio is 0.3 of the magnesium alloy.

3.2 Mechanical properties of ceramic coatings

\subsubsection{The elastic modulus of the ceramic coatings}

\subsubsection{Three points to measure elastic modulus}

The elastic modulus of three point bending method for the determination of the ceramic coatings is relatively simple, the results for the overall value of ceramic coatings, can be avoided by the microscopic defects in ceramic coatings partially caused by the uneven distribution of inaccuracy. This section presents a calculation method for three point bending specimen can be measured, elastic modulus of composite coating. Application of load and displacement of points to record the test process, and draw the load displacement curves, modulus of elasticity can be obtained through the ceramic coatings of composite beam theory [4]. The micro arc oxidation ceramic coatings by double coating, as shown in 3-4 three point bending test diagram.

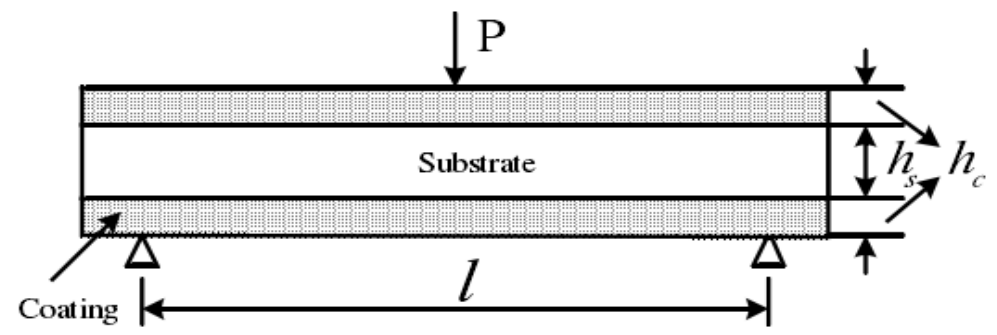

Figure 3-4 Schematic diagram of three point bending

Two side coated specimen:

$$
\begin{aligned}
2 \mathrm{E}_{\mathrm{c}} \mathrm{I}_{\mathrm{c}}+\mathrm{E}_{\mathrm{s}} \mathrm{I}_{\mathrm{s}}=3 \mathrm{Pl} / 48 \mathrm{~L} \\
\mathrm{I}_{\mathrm{s}}=\mathrm{bh}_{\mathrm{s}} 3 / 12 \\
\mathrm{I}_{\mathrm{c}}=\mathrm{bh}_{\mathrm{c}} 3 / 12
\end{aligned}
$$

Among them: I-moment of inertia, $\mathrm{P}-$ The load test of the elastic bending, $\mathrm{L}-$ The corresponding displacement of elastic stage, 1 -span, $b$ - specimen width, $\mathrm{c}$ - ceramic coatings, $\mathrm{s}$ - matrix.

The(3-4), (3-5) into(3-3), known Es, P and L can be obtained by experiment, it can be calculated the elastic modulus values of the Ec ceramic coatings. 


\subsubsection{The test process}

Three-point bending test equipment using a small bending test machine and static resistance strain gauges shown in Figure3-5. Figure3-4 placement test specimen, loading at room temperature, figure36 for the sample without loading condition, Figure3-7 the loading state of sample. Manual recording every moment plus the added load $\mathrm{P}$ and the corresponding static resistance strain gauges on the micro-strain $\mu \varepsilon$, through the micro strain values are converted to the displacement of $L$ the time point of application, in the process of test samples to ensure online within the range of elastic deformation. Figure 3-8 is a sample loading within the elastic phase-displacement curve.

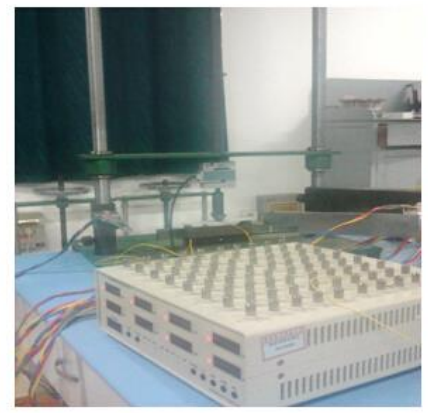

Figure 3-5

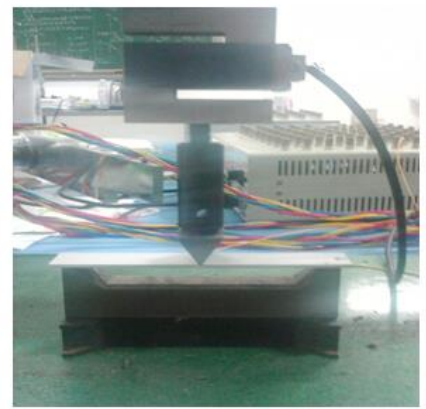

Figure 3-6

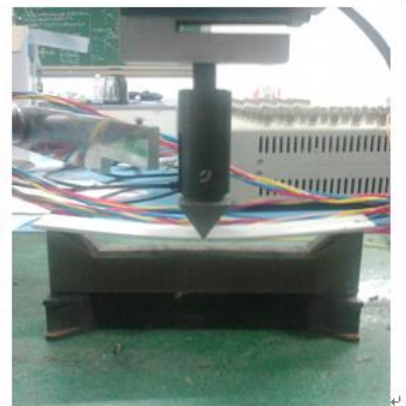

Figure 3-7

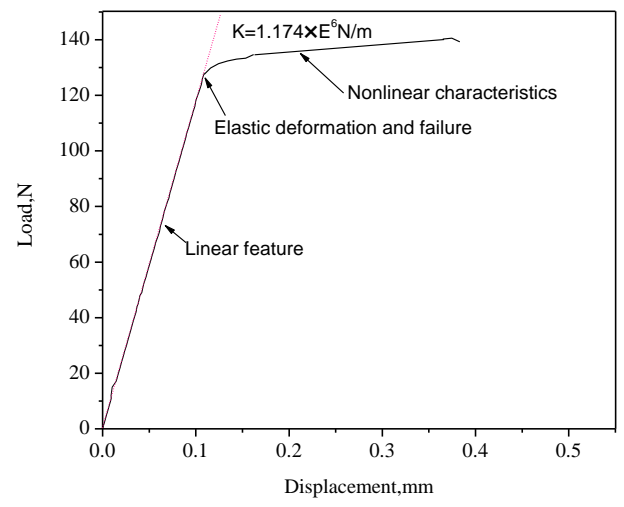

Figure 3-8 The load displacement curves of the three point bending test

Three-point bending test load - displacement curve as shown in Figure 3-8. Can be found in the initial load, the load applied to the corresponding linear relationship between the displacement. By Hooke's law $(\sigma=\mathrm{E} \times \varepsilon)[5]$ shows that, This means that the stress in the elastic deformation in the stage of loading the sample, the smaller the strain. As the load increases when $128 \mathrm{~N}$, load the sample - displacement curve inflection point, this time between the load and the corresponding displacement of the nonlinear relationship, the slope of the phase curve changed significantly, the elastic deformation of the sample mean failure, this time material plastic deformation. Therefore in the calculation of the elastic 
modulus of ceramic coatings, data should be obtained in the linear phase curve. Through the fitting of linear phase data in 3-8 diagram, can be obtained by the slope of the curve of $\mathrm{K}=1.174 \times 10^{6} \mathrm{~N} / \mathrm{m}$.

Linear load displacement curve of the test results, the type (3-3), (3-4), (3-5) can be obtained in the elastic modulus of the ceramic coatings. Through the 5 bending test and 5 times the average, the elastic modulus of ceramic coatings is $127.4 \mathrm{GPa}$. Table $3-4$ need to explain differences in 5 tests, Microstructure of the coating and the specimen.

Table 3-4 Modulus of elasticity of the ceramic coatings

Test

Test1

Test2

Test3

Test4

Test5

Average

Modulus

elasticity (Gpa)

128.9

128.1

126.7

126.4

126.9

127.4

\subsubsection{The relationship between elastic modulus and thickness}

Figure 3-9 shows the relationship between the elastic modulus and the thickness of ceramic coatings between 20-60 $\mu \mathrm{m}$ thickness. Can be found, Elastic modulus of the ceramic layer increases with increasing thickness. Mainly due to the increase in the thickness of the ceramic coatings is accompanied by its internal porosity becomes small, so that the elastic modulus increases.

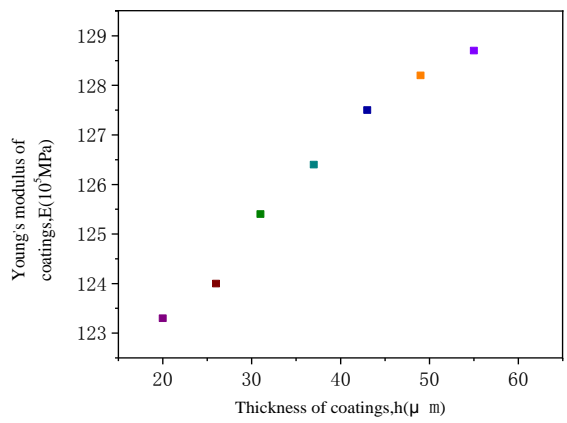

Figure 3-8 Relationship between the modulus and the thickness of ceramic coatings elastic

\subsubsection{The Poisson's ratio of ceramic coating}

The literature shows that: metal coating Poisson's ratio between $0.25-0.3[6-8]^{\mathrm{a}}$, Metal coatings on the finite element analysis, the Poisson's ratio of 0.3 were taken. As shown in table 5-2, the main component of the ceramic coatings is $\mathrm{Mg}$, it is possible to obtain a ceramic layer Poisson's ratio $\mathrm{v}=$ 0.3 .

\section{Conclusions}

1. through measurement of tensile modulus of elasticity of magnesium alloy matrix, The results show that: can get magnesium alloy matrix elastic modulus $E=50.6 \mathrm{GPa}$, Poisson's ratio $v=0.3$. 
2. three-point bending method to measure the elastic modulus of the ceramic coatings. can get microarc oxidation ceramic coatings elastic modulus $E=127.4 \mathrm{GPa}$, Poisson's ratio $v=0.3$.

3. studied the relationship elastic modulus of the ceramic coatings with the thickness of the thickness between $20-60 \mu \mathrm{m}$. The results show that: With the increaseing of the thickness, the ceramic coatings elastic modulus trend to increase.

\section{Acknowledgement}

This paper was supported by Natural Science Foundation of China (NO. 51301047and51361008) and Guilin University of Electronic Technology graduate innovation project (NO.GDYCSZ201403). And I would like to take this opportunity to thank my dear tutor, Professor Xu jinyong.

\section{References}

[1] Nix W D. Mechanical properties of thin films[J].MetalTrans,1989, 20A: 2217 2245.

[2] Wang liShi, Pan chunxu, Cai qidan, et al. Effect of micro arc oxidation film on tensile properties of die casting magnesium alloy[J]. special casting and nonferrous alloys, 2007(3): 165-169.

[3] Xu lianyong, Jing hongyang, Huo lixing, Zhang Yufeng, et al. The elastic modulus and the base metal ceramic interface fracture toughness of[J]. welding, 2006(8): 55-57

[4] Timoshenko S P, James M Gere. Mechanics of Materials. Van Nostr and Reinhold Co., Inc., Molly Millars Lane, Working ham, Berkshire, England.

[5] Qian G., Nakamura T, Berndt C.C. Tensile Toughness Test and High Temperature Fracture Analysis of Thermal Barrier Coatings.Acta Materialia, 1997, 45(4): 1767-1784.

[6] Satoh S, Tsukamoto M, Minami F. et al. Evaluation of interface strength of plasma sprayed coatings by the local approach. Proceedings of the International Conference on Offshore Mechanics and Arctic Engineering-OMAE, v 3,Materials Engineering, 1996. 157-164.

[7] Minami F, Satoh S, Tsukamoto M. Evaluation of interface strength of bonded dissimilar materials based on Weibull stress fracture criterion. Mate, 2000, 3-4:67-72.

[8] Mao weiguo, Dai cuiying, Zhou yichun. Preparation of thermal barrier coatings in the system in the process of residual stress field prediction. Journal of natural science of Xiangtan University, 2005, 27(4): 46-52. 